Brit. Heart F., 1966, 28, 147.

\title{
Use of a Computer in the Calibration of Dye Dilution Curves by a Dynamic Method
}

\author{
JOHN HAMER $\star$ RICHARD EMANUEL, JOHN NORMAN, AND MARY BURGESS \\ From the Institute of Cardiology, the National Heart Hospital, and the Institute of Clinical Research, \\ Middlesex Hospital, London W.1
}

The dynamic method for calibration of continuously recorded indicator dilution curves described by Sparling et al. (1960) gives measurements of flow comparable to those obtained from a timed collection of fluid in a model system (Emanuel and Norman, 1963) and from the multiple arterial sample method of Hamilton et al. (1928) in the dog (Emanuel et al., 1966). The dynamic method relies on the production of a second indicator dilution curve from a small calibration system through which the flow is known, and avoids the need for the direct estimation of concentrations of indicator in blood.

The calculation of cardiac output by indicator dilution methods requires measurement of the area of the dilution curve after the effects of recirculation have been eliminated. The area representing the primary circulation is usually obtained by reconstructing the decay slope on the assumption that the fall in the concentration of indicator is exponential (Hamilton et al., 1928). The measurement of cardiac output in this way is therefore a lengthy procedure. The recent development of computers for measuring the relevant area of the dilution curve allows the results to be obtained more rapidly, greatly enhancing the value of the method.

The present report describes the application of a computer to the dynamic method of calibration of indicator dilution curves in the dog. The computer was used to measure the area of the dilution curves from the animal and from the calibration system. The cardiac output obtained from computed dilution curves was compared to the output calculated from planimetric measurements.

Received May 17, 1965.

$\star$ Present address: Saint Bartholomew's Hospital, London E.C.I.

\section{METHODS}

In dogs under general anæsthesia one femoral artery was cannulated and the cardiac output was measured from continuously recorded indicator dilution curves, using the dynamic method of calibration as described in the previous report (Emanuel et al., 1966). The curves were recorded on a Honeywell Controls Ltd. potentiometric recorder, and the areas were measured by planimetry after replotting the exponential decay slope to eliminate the effects of recirculation. The cardiac output measured in this way was compared to the output obtained from the computed curve areas. The voltage at the slide wire of the potentiometric recorder was applied to a Lexington Instruments "Cardiac Output Computer" (Fig. 1), which gives a continuous estimate of the area of the indicator dilution curve, plus the area enclosed by the exponential, as the curve is described. The output of the computer is recorded on the same chart as the original curve, with a slight time lag (Fig. 2). When the concentration of indicator is falling exponentially the computer gives a steady reading. The value computed at this point indicates the area of the indicator dilution curve after the effects of recirculation have been eliminated. If no true exponential slope occurs, there is no horizontal section of the computed curve and calculation of the cardiac output is not possible (see Fig. 5).

A comparison of the cardiac outputs calculated by the two methods in 40 consecutive measurements from 4 greyhounds is reported. Towards the end of each study approximately $100 \mathrm{ml}$. of blood were discarded between successive measurements of cardiac output, in order to assess the validity of the method under varying conditions.

\section{RESULTS}

The range of cardiac outputs measured in this study was from 1.3 to $7.41 . / \mathrm{min}$. (Table). The percentage error of the computed measurements was between -9 per cent and +8 per cent, with a mean error of -0.9 per cent (standard deviation 


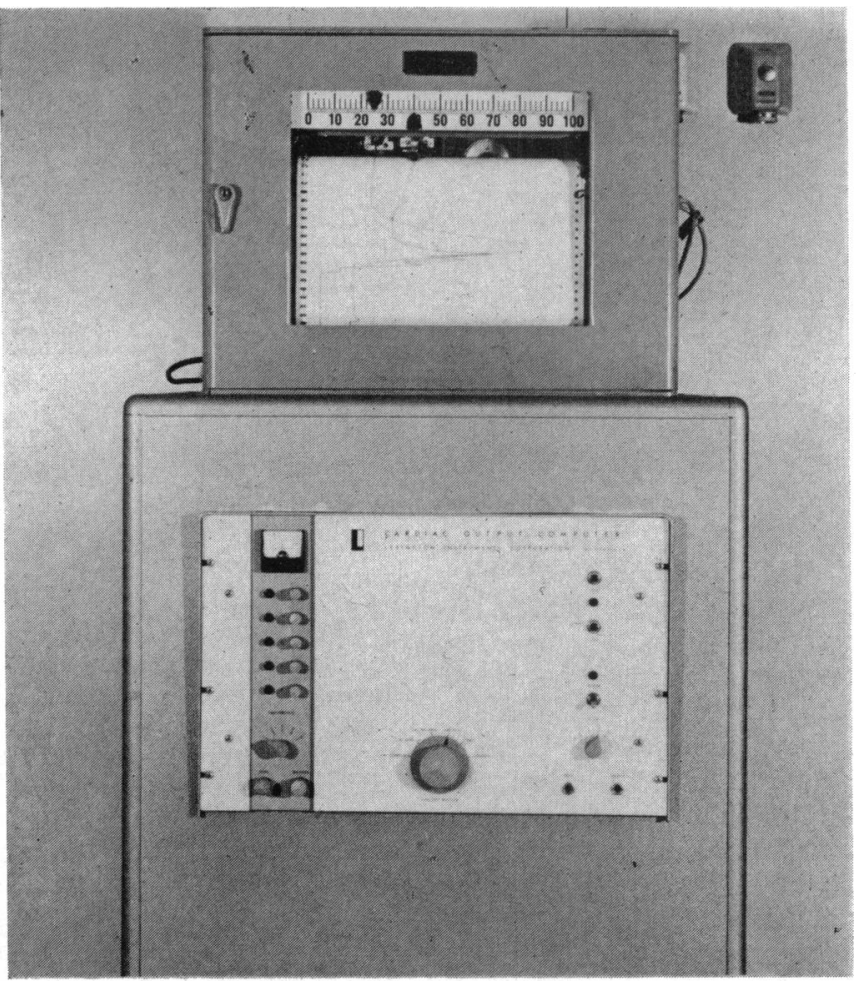

Fig. 1.-The Lexington Cardiac Output Computer is shown mounted in a portable trolley with the Honeywell potentiometric recorder.

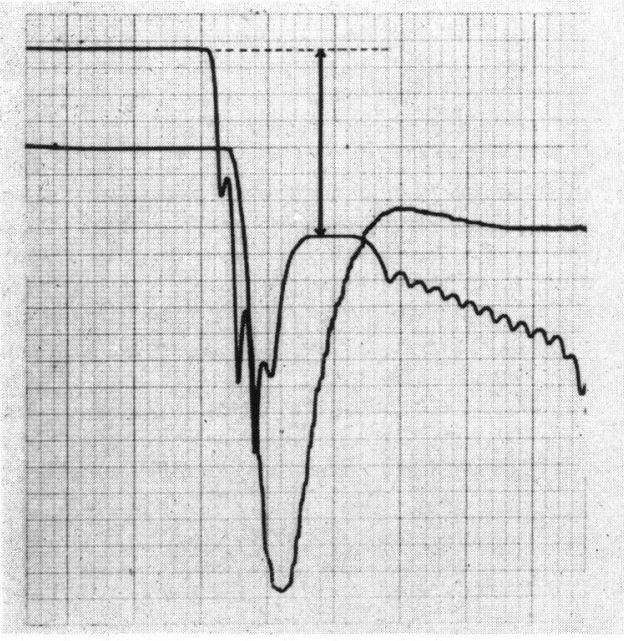

ANIMAL CURVE

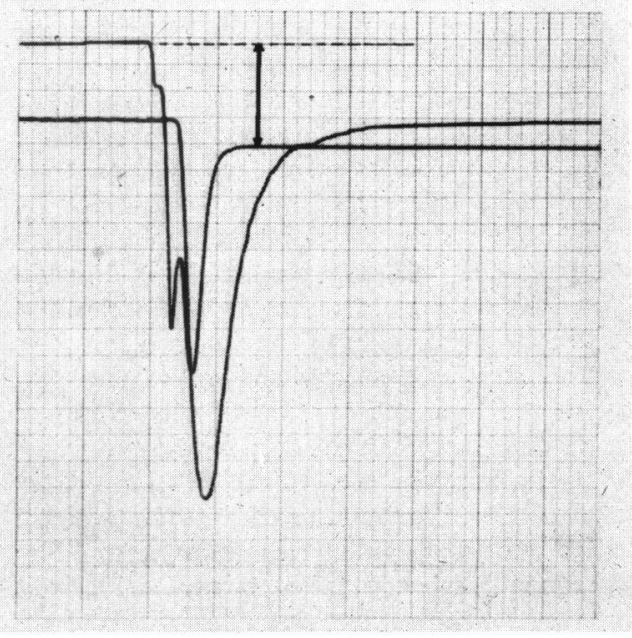

CALIBRATION CURVE

Fig. 2.-Typical indicator dilution curves and computed curve areas. The indicator dilution curve and the output of the computer are shown on the same chart. The computed value reaches a steady reading when the decay of the dilution curve becomes exponential. The computed value at this point, indicated by the arrow, is proportional to the curve area for the primary circulation. In the curve from the animal (left), recirculation disturbs the exponential slope and the computed value rises again. The curve from the calibration system (right) continues to decay exponentially. 


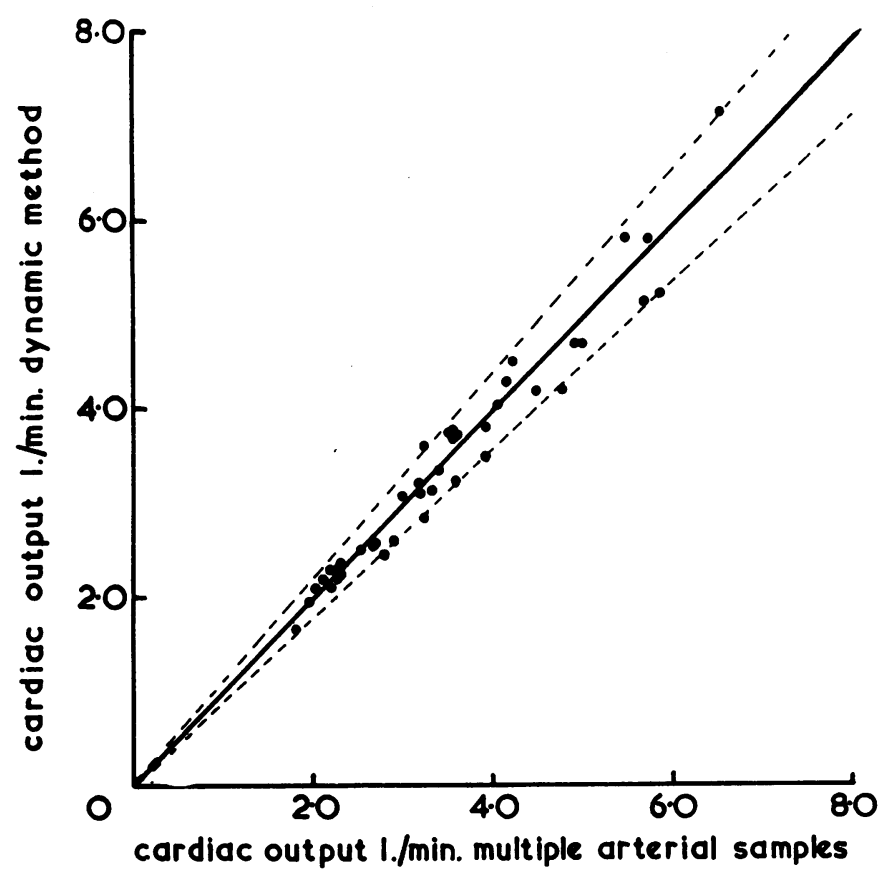

Fig. 3.-Comparison of cardiac outputs by computer and by planimetry. The computed outputs are within \pm 10 per cent (as shown by the dotted lines) of the values obtained by planimetry.

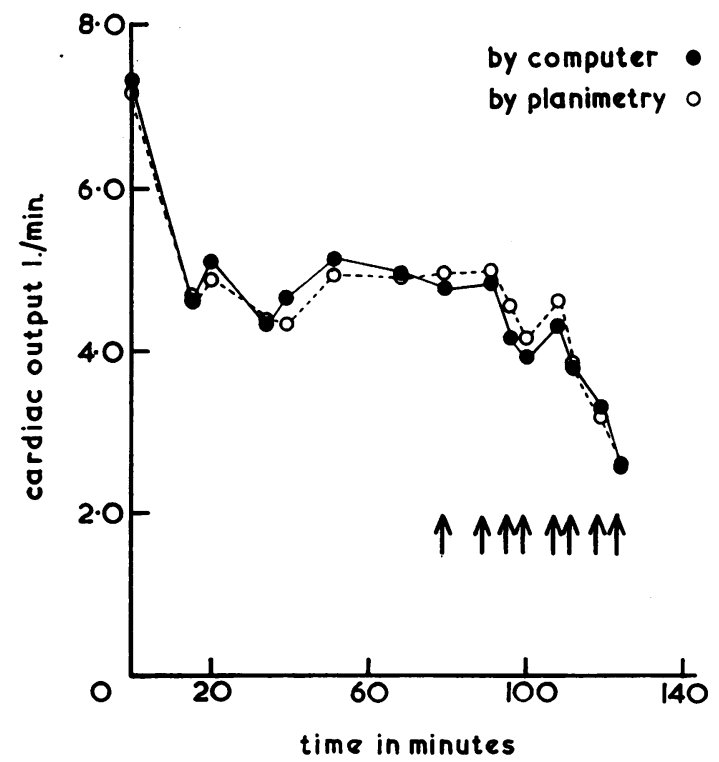

Fig. 4.- Changes in cardiac output by the two methods. The variations in cardiac output throughout a single experiment are shown. Each arrow indicates that $100 \mathrm{ml}$. of blood were discarded. Corresponding indicator dilution curves are shown in Fig. 5.
4.4 \%). There was therefore a 95 per cent probability that the computed cardiac output was between -10 per cent and +8 per cent of the value obtained by planimetry (Fig. 3 ).

In two dogs the variation in cardiac output was followed over a period of 2 hours (Fig. 4). The reduction in cardiac output and distortion of the indicator dilution curve produced by blood loss did not reduce the comparative accuracy of the two methods. The duration of the exponential slope of the indicator dilution curves as judged by the computer varied from 1 to $7 \mathrm{sec}$. There was little relation between the length of the exponential section and the cardiac output, but there was a tendency to a shorter exponential slope after repeated bleedings in some studies (Fig. 5). In one animal, after considerable bleeding, a curve with no exponential portion was obtained (Fig. 5), and the output could not be calculated.

\section{Discussion}

There was no significant difference between the cardiac output obtained by planimetry and from the computer under the conditions of the present study. The combination of the dynamic method of calibration and the use of a computer to measure the areas 


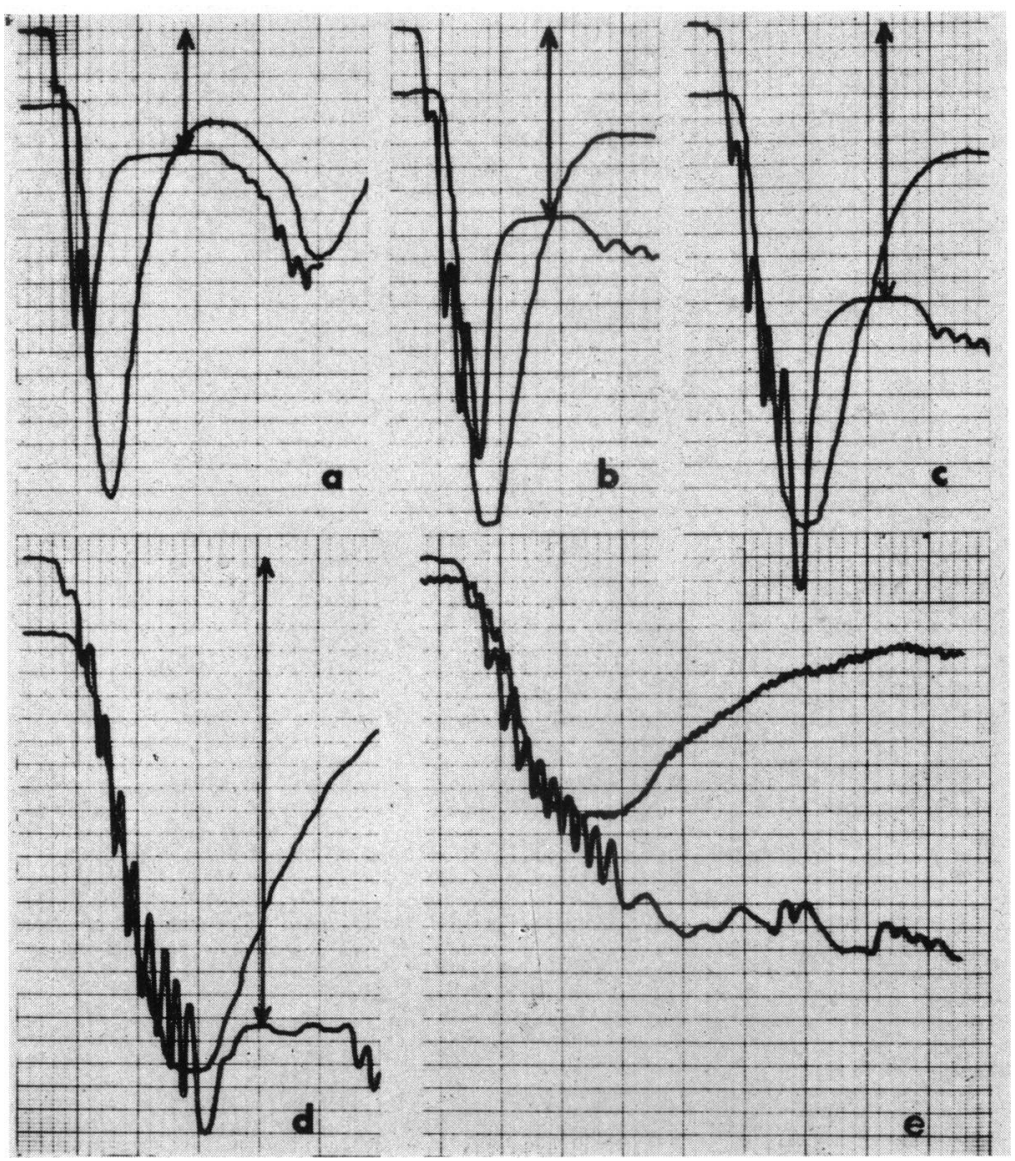

FIG. 5.-Effect of repeated bleeding on indicator dilution curves. In one animal (a, b, and c) the cardiac output fell from 7.35 to 3.78 to $2.59 \mathrm{l}$./min. with corresponding increases in the curve area (shown by the height of the arrows), but the length of the exponential section of the decay slope (shown by the horizontal portion of the computed curve) is relatively unaffected. In another study (d) a low cardiac output (1.35 1./min.) and a large curve area were found after repeated bleeding, but the exponential section of the decay slope was short. After further blood loss in this animal (e), a curve was obtained with no exponential decay slope. The computer reading did not reach a steady value and the cardiac output could not be calculated.

of the dilution curves greatly facilitates the calculation of the cardiac output by the dilution method. Repeated measurements can be made at frequent intervals without difficulty.

The use of a computer of this type to analyse indicator dilution curves is open to criticism, as a theoretical justification cannot be provided for the assumption of an exponential decay in the concentration of indicator (Zierler, 1962). Many factors influence the decay slope, but nevertheless an approximately exponential pattern is usually found; presumably washout from a single mixing chamber predominates (Newman et al., 1951). The hypothesis of an exponential slope, first postulated by Hamilton et al. (1928), has in fact proved a practical method for eliminating the effects of recirculation. Any error produced by this assumption will be masnified by situations producing indicator dilution curves of large area and slow decay, e.g. low cardiac output, large central blood volume, and valvar incompetence.

In the present study an exponential slope was demonstrated by the computer in $\mathbf{4 0}$ experiments with various cardiac outputs and circulating blood volumes. On theoretical grounds it might be expected that an increase in the width of the curve as a result of a reduction in cardiac output would be associated with delayed recirculation, so that the exponential section of the curve would be relatively little affected. On the other hand, widening of the 
TABLE

COMPARISON OF CALCULATED AND COMPUTED CARDIAC OUTPUTS IN

40 CONSECUTIVE EXPERIMENTS

\begin{tabular}{|c|c|c|c|}
\hline $\begin{array}{l}\text { Experiment } \\
\text { No. }\end{array}$ & $\begin{array}{c}\text { Calculated } \\
\text { output }(1 . / \mathrm{min} .)\end{array}$ & $\begin{array}{l}\text { Computed } \\
\text { output (1./min.) }\end{array}$ & $\begin{array}{c}\text { Percentage } \\
\text { error }\end{array}$ \\
\hline 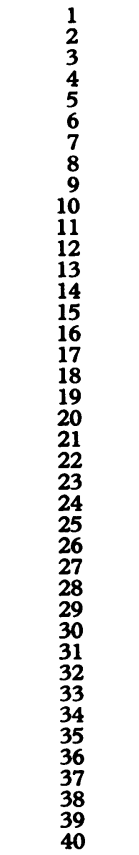 & 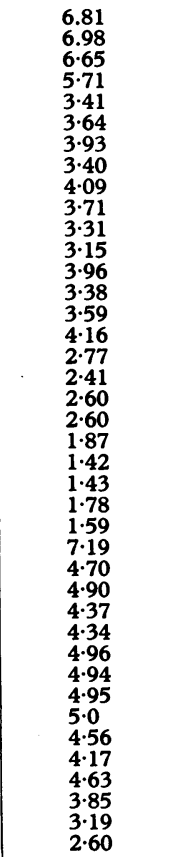 & $\begin{array}{l}6 \cdot 57 \\
6 \cdot 93 \\
6 \cdot 22 \\
5 \cdot 78 \\
3 \cdot 32 \\
3 \cdot 56 \\
4 \cdot 11 \\
3 \cdot 23 \\
3 \cdot 72 \\
3 \cdot 49 \\
3 \cdot 18 \\
2 \cdot 94 \\
4 \cdot 09 \\
3 \cdot 25 \\
3 \cdot 66 \\
4 \cdot 14 \\
2 \cdot 99 \\
2 \cdot 33 \\
2 \cdot 56 \\
2 \cdot 75 \\
1 \cdot 88 \\
1 \cdot 35 \\
1 \cdot 47 \\
1 \cdot 77 \\
1 \cdot 58 \\
7.35 \\
4 \cdot 62 \\
5 \cdot 13 \\
4 \cdot 35 \\
4 \cdot 67 \\
5 \cdot 15 \\
4.96 \\
4 \cdot 79 \\
4 \cdot 85 \\
4 \cdot 16 \\
3 \cdot 92 \\
4 \cdot 30 \\
3 \cdot 78 \\
3 \cdot 31 \\
2 \cdot 59\end{array}$ & $\begin{array}{l}-3.5 \\
-0.7 \\
-6.5 \\
+1.2 \\
-2.6 \\
-2.2 \\
+4.6 \\
-5.0 \\
-9.0 \\
-5.9 \\
-3.9 \\
-6.7 \\
+3.3 \\
+3.9 \\
+1.9 \\
-0.5 \\
+7.9 \\
-3.3 \\
-1.5 \\
+5.8 \\
+0.5 \\
-4.9 \\
+2.8 \\
-0.6 \\
-0.6 \\
+2.2 \\
-1.7 \\
+4.7 \\
-0.5 \\
+7.6 \\
+3.8 \\
+0.4 \\
-3.2 \\
-3.0 \\
-8.8 \\
-6.0 \\
-7.1 \\
-11.8 \\
+3.5 \\
-0.4\end{array}$ \\
\hline
\end{tabular}

curve by an increase in central blood volume or valvar regurgitation would be expected to reduce the exponential portion of the decay slope. Changes of this type were produced by blood loss in the present study (Fig. 5). The accuracy of the measurement of cardiac output was not usually affected as a brief exponential decay slope was clearly indicated. However, in the most severely affected curve no exponential portion was detected by the computer (Fig. 5); curves of this type cannot be used for the measurement of cardiac output, and the computer provides a useful check on the suitability of a given curve for analysis.

\section{SUMMARY}

Cardiac output measurements from continuously recorded indicator dilution curves in greyhounds were calibrated by the dynamic method. The results obtained by planimetric measurement of curve areas were used as a basis for the assessment of a computer which estimated the area of the curves after eliminating the effects of recirculation. In 40 consecutive experiments there was a 95 per cent probability that the estimations of cardiac output by the two methods were within -10 per cent to +8 per cent of each other. The cardiac output in these studies was between 1.3 and $7.41 . / \mathrm{min}$. The computer provides evidence of the suitability of each curve for analysis, and when used with the dynamic method of calibration greatly reduces the time needed to estimate the cardiac output by the indicator dilution method.

\section{REFERENCES}

Emanuel, R., Hamer, J., Chiang, B-N., Norman, J., and Manders, J. (1966). A dynamic method for the calibration of dye dilution curves in a physiological system. Brit. Heart f., 28, 143.

-, and Norman, J. (1963). Evaluation of a dynamic method for calibration of dye dilution curves. Brit. Heart f., 25, 308.

Hamilton, W. F., Moore, J. W., Kinsman, J. M., and Spurling, R. G. (1928). Simultaneous determination of the greater and lesser circulation times, of the mean velocity of blood flow through the heart and lungs, of the cardiac output and an approximation of the amount of blood actively circulating in the heart and lungs. Amer. $\mathcal{F}$. Physiol., 85, 377.

Newman, E. V., Merrell, M., Genecin, A., Monge, C., Milnor, W. R., and McKeever, W. P. (1951). The dye dilution method for describing the central circulation. An analysis of factors shaping the time-concentration curves. Circulation, 4, 735.

Sparling, C. M., Mook, G. A., Nieveen, J., Van der Slikke, L. B., and Zijlstra, W. G. (1960). Calibration of dye dilution curves for calculating cardiac output and central blood volume. In C.R. 3e Congrès Européen de Cardiologie, Rome, Pars altera A, p. 595, Excerpta Medica.

Zierler, K. L. (1962). Circulation times and the theory of indicator-dilution methods for determining blood flow and volume. In Handbook of Physiology, Section 2: Circulation, ed. W. F. Hamilton, and P. Dow, Volume 1, p. 585. American Physiological Society, Washington, D. C. 